\title{
Importance of Human Development and Challenges
}

\author{
${ }^{1}$ Truc Nhan and ${ }^{2}$ Dao ba Loc \\ ${ }^{1,2}$ School of Design, Van Lang University, Thanh pho Ho Chi Minh 700000, Vietnam. \\ ${ }^{1}$ Nhantrucvan@aol.com
}

\author{
Article Info \\ Journal of Journal of Enterprise and Business Intelligence (http://anapub.co.ke/journals/jebi/jebi.html) \\ Doi: https://doi.org/10.53759/5181/JEBI202101017 \\ Received 12 March 2021; Revised form 10 April 2021; Accepted 05 May 2021. \\ Available online 05 July 2021. \\ (C)2021 Published by AnaPub Publications.
}

\begin{abstract}
Vietnam has achieved many achievements in human development, which is reflected in the increase in HDI rankings, increase in component indexes as well as HDI value, the growth rate of HDI among the highest in the world but there are many challenges that Vietnam needs to overcome to get higher HDI. This research collected and analyzed secondary data to analyze, compare and evaluate data on HDI, IHDI, inequality, gender gap, disparities in regions and people groups and some other related indicators to indicate Viet Nam's achievements in human development since 1990, and more importantly, the study identified challenges in gender gaps, disparities in regions and people groups. In order to overcome these challenges and increase HDI much more, based on the analysis of the state of Vietnam's human development and its challenges, the study proposed some policy suggestions such as: (1) Closing the gender gap in education and labor participation; (2) Reducing disparities among regions and population groups; (3). Improving the access ability to education and health care for the poor; (4) Improving people's income and quality of life.
\end{abstract}

Keywords - HDI, Human Development, Vietnam, Inequality, MPI,

\section{INTRODUCTION}

Performing the economic and political reforms under Doi Moi in over 30 years, Vietnam has promoted rapid economic growth, achieved a great transformation from one of the poorest in the world to a lower middle-income country. Vietnam is considered as Asia's Newest Tiger Economy by prestigious organizations in the world. Because this country has the stable political and social background, the increasingly improved infrastructure and business environment, and the attractive investment environment for international investors. However, Vietnam still has many difficulties and challenges to achieve its goal of becoming a prosperous nation. The role of the human factor and the human resource will be increasingly important for Vietnam to reach its goals of prosperity with two pillars: rapid growth and sustainable development.

The Human Development Index (HDI) reflects a nation's average level of attainment of basic human capabilities, determining whether people have long and healthy lives, are educated knowledge and enjoy a decent living standard or not. The report "Human Development Indicators: Updated Vietnam's 2018 Statistics" by the United Nations Development Program [1] shows that Human Development Index (HDI) Vietnam's growth has been increasing steadily for the past 27 years but it is tending to level off. Viet Nam has achieved lots of good results in Human Development, has become one of the countries with the highest growth rate of HDI in the world, with an average HDI growth rate of $1.36 \%$ in the period of 1990 - 2018. Currently, Vietnam's HDI is just below the high human development threshold of 0.007 points. Thus, what are hindering the development of human in Vietnam? Finding out these difficulties or challenges is very important for Vietnam. Because the analysis of these issues is the basis to propose solves to overcome them in order to promote human development, help Vietnam enter the high human development group. This study focuses on analyzing Vietnam's achievements in human development, while also finding challenges in this issue. On that basis, the study proposes a number of policy suggestions to solve difficulties, overcome challenges and promote Vietnam's human development in the coming time.

The organization of the next sections is as follows. Section 2, addressing the researches related to the human development. While, proposed research methodology is introduced in section 3. Then the result, discussion and the conclusion are presented in section 4 and 5; respectively.

\section{LITERATURE REVIEW}

In the human development report 1990, UNDP introduced the concept "Human development is a process of enlarging people's choices. In principle, these choices can be infinite and change over time. But at all levels of development, the 
three essential ones are for people to lead a long and healthy life, to acquire knowledge and to have access to resources needed for a decent standard of living." [2]

The human development in Vietnam is concerned and researched by many Vietnamese and international organizations and experts. UNDP annually reports on Viet Nam's human development, providing the most up-to-date information and data, covering component indicators and many aspects of Viet Nam's human development as well as compared to other countries [3]. In addition, many studies of scientists have analyzed and assessed human development issues in Vietnam in many aspects. [4] found that governance mostly affects HDI in aspects of political freedoms, and political participatory, meanwhile less affects the aspects of income, health and education. Based on this result, the research proposed some suggestions on improvement of governance aim to sustain human development of the country. People are the central element, the most special and important resource for economic development. Human capital is crucial to national economic growth. [5] in the study "Vietnam - Human Capital as a Key Driver for Economic Growth - An Investigation of Vietnam's Economy and Binding Constraints" emphasized the role of human capital and recommended a number of policies to develop education and training, improve the quality of human resources, strengthen the role of government in connecting schools with the employer. The results of this study also aim to improve the education index to improve the human development index. In addition, the environment is also a factor affecting human development. Researchers are especially concerned about climate change. This current issue has been affecting the lives of people as well as the human development of Vietnam. This issue was analyzed and evaluated in the study "Climate Change and Human Development in Vietnam: a case study" of [6]. Also, on this topic, [7] in the study "Human development of Vietnam in the face of challenges of climate change" analyzed the impacts of climate change on development resources, national welfare, food security, poverty reduction, human health, politics and society.

For the multi-ethnic country as Vietnam with 54 ethnic groups distributed over 63 provincial administrative units, in which, each ethnic has its own language, lifestyle, and cultural heritage, there are disparities among ethnic groups in living conditions, poverty rates, this affects the country's HDI adjustment. The research Report "Drivers of SocioEconomic Development among Ethnic Minority Groups in Vietnam" was implemented by Australia - World Bank Group strategic partnership in Vietnam [8] showed that the multidimensional poverty index (MPI) for each ethnic group helps to supplement the HDI approach. This report ranked HDI by ethnic minorities, showing disparities in human development levels among ethnic groups.

A number of studies on human development issues in Southeast Asia including analysis and evaluation of Vietnam such as the research "Income Elasticity of Human Development in ASEAN Countries" of [9] focused on the impact of Income Elasticity on Human Development, or in the research "Determinant of Human Development Index in ASEAN Countries" of [10] determined the factors affecting HDI in ASEAN countries. This research used the regression analysis method. The results have showed that HDI in ASEAN countries was affected by population and the per capita income growth rate, meanwhile it was not affected by inflation rate and unemployment rate.

From the review of the above studies, human development studies in Vietnam or Southeast Asian countries with content from general overview to some aspects such as governance, human capital, Climate Change, Income Elasticity, Determinant of Human Development Index and disparities in ethnic or people group. However, in order to analyze and promote human development, many studies in other countries have mentioned aspects of inequality, gender inequality and regional disparities.

These studies show that the issue of gender inequality, regional inequality or regional disparities affects the HDI index or human development of each country. However, these aspects have not been mentioned much in human development studies in Vietnam. This is the knowledge gap, suggesting new research directions, in that the scientists could research Vietnam's human development in overview as well as in its aspects, with a comparison in the time series from year 1990 (the year of the first human development report of UNDP was issued) until 2018, compare HDI of Vietnam with other countries, groups of countries by human development level, countries by region, as well as an indepth analysis of Vietnam's HDI indices through analysis of IHDI index, the loss in HDI due to inequality, gender gap or gender inequality, disparities in regions and people groups in order to find out the causes that hinder the human development in Vietnam.

\section{RESEARCH METHODS}

The data used in the study are secondary data collected and aggregated from official reports of the United Nations Development Program [9], General Statistics Office of Vietnam.

The study used the analysis and comparison method of HDI, IHDI, GII, MPI, human inequality index, and some other related indicators of Vietnam, specifically comparing with 10 selected countries (India, Laos, Myanmar, Cambodia, South Korea, Malaysia, Thailand, China, Philippines and Indonesia) and with two groups of countries (High Human Development, Medium Human Development) and with East Asia and the Pacific. In addition, the comparative method is also used to analyze the fluctuation of HDI and component indexes of Vietnam from 1990 to 2018. 


\section{RESULTS AND DISCUSSION}

Achievements in term of human development in Vietnam

Vietnam's progress in human development

Viet Nam has obtained lots of remarkable achievements in human development, with an average annual Human Development Index (HDI) growth of 1.36 percent in the period of 1990-2018, join in the group of countries with the highest HDI growth rates in the world.

Table 1: Vietnam's HDI and component indicators

\begin{tabular}{cccccc}
\hline Year & $\begin{array}{c}\text { Life expectancy } \\
\text { at birth (years) }\end{array}$ & $\begin{array}{c}\text { Expected years of } \\
\text { schooling (years) }\end{array}$ & $\begin{array}{c}\text { Mean years of } \\
\text { Schooling (years) }\end{array}$ & $\begin{array}{c}\text { GNI per capita } \\
(\mathbf{2 0 1 1} \text { PPP\$) }\end{array}$ & HDI value \\
\hline 1990 & 70.6 & 7.8 & 3.9 & 1,369 & 0.475 \\
1995 & 71.9 & 9.3 & 4.6 & 1,944 & 0.529 \\
2000 & 73.0 & 10.6 & 5.4 & 2,725 & 0.578 \\
2005 & 74.1 & 11.3 & 6.4 & 3,367 & 0.616 \\
2010 & 74.8 & 12.0 & 7.5 & 4,266 & 0.653 \\
2015 & 75.1 & 12.7 & 8.0 & 5,314 & 0.68 \\
2016 & 75.2 & 12.7 & 8.1 & 5,638 & 0.685 \\
2017 & 75.2 & 12.7 & 8.2 & 5,916 & 0.69 \\
2018 & 75.3 & 12.7 & 8.2 & 6,220 & 0.693 \\
\hline
\end{tabular}

(Source: UNDP, 2020)

Table 1 reviews Viet Nam's progress in each of the HDI indicators. Between 1990 and 2018, Viet Nam's HDI value increased from 0.475 to 0.693 , an increase of 45.9 percent. Besides, the component indicators also increased significantly. Viet Nam's life expectancy at birth increased from 70.6 to 75.3 (an increase of 4.7 years), mean years of schooling increased from 3.9 to 8.2 (an increase of 4.3 years) and expected years of schooling increased from 7.8 to 12.7 (an increase of 4.9 years). Viet Nam's GNI per capita increased from $\$ 1369$ to $\$ 6220$ (an increase of $\$ 4851,5.55 \%$ in the period of 1990 - 2018).

Regarding the HDI, Vietnam is currently in the High Medium category, with an index value of 0.693 in 2018. Vietnam had an average annual HDI growth of 1.36 percent, the 20th best rate of all countries and territories. However, the process of improving HDI over the past three decades has been uneven. From 1980 to 1990, the HDI increased on average by $0.26 \%$ per year, from 1990 to 2000 accelerated to $2 \%$ per year. But in the period of $2000-2008$, HDI decreased to about $1.35 \%$ / year and the following period continued to average $0.94 \%$ / year.

Human development of Vietnam compared to other countries

With the HDI index of 2018 of 0.693 , Vietnam currently ranks 118/189 countries and territories in this index, standing at the second highest position among the countries with Medium human development. Vietnam will have ability to join the High Human Development group if Vietnam's HDI gains additional 0.007 points.

Table 2 shows that Vietnam's HDI in 2018 is 0.693 , higher than the HDI value (0.634) of the Medium Human Development group, but below the HDI value (0.750) of the High Human Development group and below the HDI value (0.741) of countries in the East Asia and Pacific region. Compared with some other countries, Vietnam's HDI rank is higher than India (129), Laos (140), Myanmar (145) and Cambodia (146), but lower than countries: South Korea (22), Malaysia. (61), Thailand (77), China (86), Philippines (106) and Indonesia (111).

Table 2: Viet Nam's HDI and component indicators in 2018 compared to selected countries and groups

\begin{tabular}{rrrrrrr}
\hline Country / Region & $\begin{array}{c}\text { HDI } \\
\text { rank }\end{array}$ & $\begin{array}{c}\text { HDI } \\
\text { value }\end{array}$ & $\begin{array}{c}\text { Life expectancy } \\
\text { at birth (years) }\end{array}$ & $\begin{array}{c}\text { Expected years } \\
\text { of schooling } \\
\text { (years) }\end{array}$ & $\begin{array}{c}\text { Mean years of } \\
\text { schooling } \\
\text { (years) }\end{array}$ & $\begin{array}{c}\text { GNI per capita } \\
\text { (2011 PPP US\$) }\end{array}$ \\
\hline Korea (Republic of) & 22 & 0.906 & 82.8 & 16.4 & 12.2 & 36,757 \\
Malaysia & 61 & 0.804 & 76.0 & 13.5 & 10.2 & 27,227 \\
Thailand & 77 & 0.765 & 76.9 & 14.7 & 7.7 & 16,129 \\
China & 86 & 0.758 & 76.7 & 13.9 & 7.9 & 16,127 \\
Philippines & 106 & 0.712 & 71.1 & 12.7 & 9.4 & 9,540 \\
Indonesia & 111 & 0.707 & 71.5 & 12.9 & 8.0 & 11,256 \\
Vietnam & 118 & 0.693 & 75.3 & 12.7 & 8.2 & 6,220 \\
India & 129 & 0.647 & 69.4 & 12.3 & 6.5 & 6,829 \\
Laos & 140 & 0.604 & 67.6 & 11.1 & 5.2 & 6,317 \\
\hline
\end{tabular}




\begin{tabular}{rcccccc}
\hline Myanmar & 145 & 0.584 & 66.9 & 10.3 & 5.0 & 5,764 \\
$\begin{array}{r}\text { Cambodia } \\
\text { High human }\end{array}$ & 146 & 0.581 & 69.6 & 11.3 & 4.8 & 3,597 \\
$\begin{array}{r}\text { development } \\
\text { Medium human }\end{array}$ & - & 0.75 & 75.1 & 13.8 & 8.3 & 14,403 \\
$\begin{array}{r}\text { development } \\
\text { East Asia and the }\end{array}$ & - & 0.634 & 69.3 & 11.7 & 6.4 & 6,240 \\
Pacific & - & 0.741 & 75.3 & 13.4 & 7.9 & 14,611 \\
\hline
\end{tabular}

The data on Vietnam's HDI and component indicators compared to countries with higher levels of human development show that the biggest reason for Vietnam's lower HDI is due to lower GNI per capita (6,220 USD). Compared to the Philippines (it's HDI is 0.712 , being in the group of high HDI countries, ranked 106th, with GNI per capita index of 9,540 USD), Vietnam has HDI with a lower value of 0.019 points, GNI per capita lower value of 3,320 USD than Philippines. In addition to the cause of per capita income, Vietnam's educational indicators are also the reason for Vietnam's HDI lower than many countries, which need to be improved. Therefore, in order to improve HDI in the coming time, Vietnam needs to focus on implementing effective measures to improve the per capita income and education indicators.

\section{Inequality-adjusted HDI (IHDI) of Vietnam}

Vietnam has obtained remarkable achievements in human development due to inequality-adjusted HDI smaller than many other countries in the Asia and the Pacific region. Viet Nam's HDI for 2018 was 0.693 . However, when the value was discounted due to inequality, the HDI value decrease to 0.580 (a loss of 16.3 percent) due to inequality in the HDI component indices. Vietnam was the country that has the second lowest rate of loss in human development in the compared countries group (the lowest is from China with 16.1\%). Despite the lower HDI ranking, the rate of "loss" in human development in Vietnam is smaller than in the Philippines (18.2\%), Thailand (16.9\%) and Indonesia (17.4\%), smaller than the average rate of medium human development group (25.9\%) and average rate of East Asia and Pacific region $(16.6 \%)$, as shown in table 3 .

Table 3: Vietnam's IHDI in 2018 compared to selected countries and groups

\begin{tabular}{|c|c|c|c|c|c|c|}
\hline \multirow{2}{*}{$\begin{array}{l}\text { HDI ranking, } \\
\text { Country/ } \\
\text { Region }\end{array}$} & \multicolumn{2}{|r|}{ IHDI } & \multirow{2}{*}{$\begin{array}{c}\begin{array}{c}\text { Human inequality } \\
\text { coefficient }\end{array} \\
(\%)\end{array}$} & \multirow{2}{*}{$\begin{array}{c}\begin{array}{c}\text { Inequality in life } \\
\text { expectancy at } \\
\text { birth }\end{array} \\
\% \\
\end{array}$} & \multirow{2}{*}{$\begin{array}{c}\begin{array}{c}\text { Inequality in } \\
\text { education }\end{array} \\
\%\end{array}$} & \multirow{2}{*}{$\begin{array}{c}\begin{array}{c}\text { Inequalit } \\
y \text { in } \\
\text { income }\end{array} \\
\%\end{array}$} \\
\hline & Value & $\begin{array}{c}\text { Overall loss } \\
(\%)\end{array}$ & & & & \\
\hline 22 Korea (Republic of) & 0.777 & 14.3 & 13.9 & 3.0 & 18.5 & 20.2 \\
\hline 77 Thailand & 0.635 & 16.9 & 16.7 & 7.9 & 18.3 & 23.8 \\
\hline 85 China & 0.636 & 16.1 & 15.6 & 7.9 & 11.7 & 27.4 \\
\hline 106 Philippines & 0.582 & 18.2 & 17.8 & 15.3 & 10.1 & 28.1 \\
\hline 111 Indonesia & 0.584 & 17.4 & 17.4 & 13.9 & 18.2 & 20.1 \\
\hline 118 Vietnam & 0.58 & 16.3 & 16.2 & 12.9 & 17.6 & 18.1 \\
\hline 129 India & 0.477 & 26.3 & 16.8 & 19.7 & 38.7 & 18.8 \\
\hline 140 Laos & 0.454 & 24.9 & 24.8 & 22.6 & 31.3 & 20.3 \\
\hline 145 Myanmar & 0.448 & 23.2 & 23.2 & 22.8 & 26.9 & 19.9 \\
\hline 146 Cambodia & 0.465 & 20.1 & 19.9 & 18.1 & 27.3 & 14.3 \\
\hline $\begin{array}{l}\text { High human } \\
\text { development }\end{array}$ & 0.615 & 17.9 & 17.5 & 10.0 & 14.8 & 27.9 \\
\hline $\begin{array}{r}\text { Medium human } \\
\text { development }\end{array}$ & 0.47 & 25.9 & 20.0 & 20.5 & 36.3 & 19.6 \\
\hline East Asia and the & & & & & & \\
\hline Pacific & 0.618 & 16.6 & 16.3 & 9.8 & 13.5 & 25.6 \\
\hline
\end{tabular}

(Source: UNDP, 2020)

The human development of a nation will decrease when nation's inequality increase. Therefore, to obtain high HDI, reducing inequality is necessary. The chart below shows the inequality and component indicators of inequality in education, healthcare and income in Vietnam in 2018 compared to selected countries and groups, as shown in figure 1. 


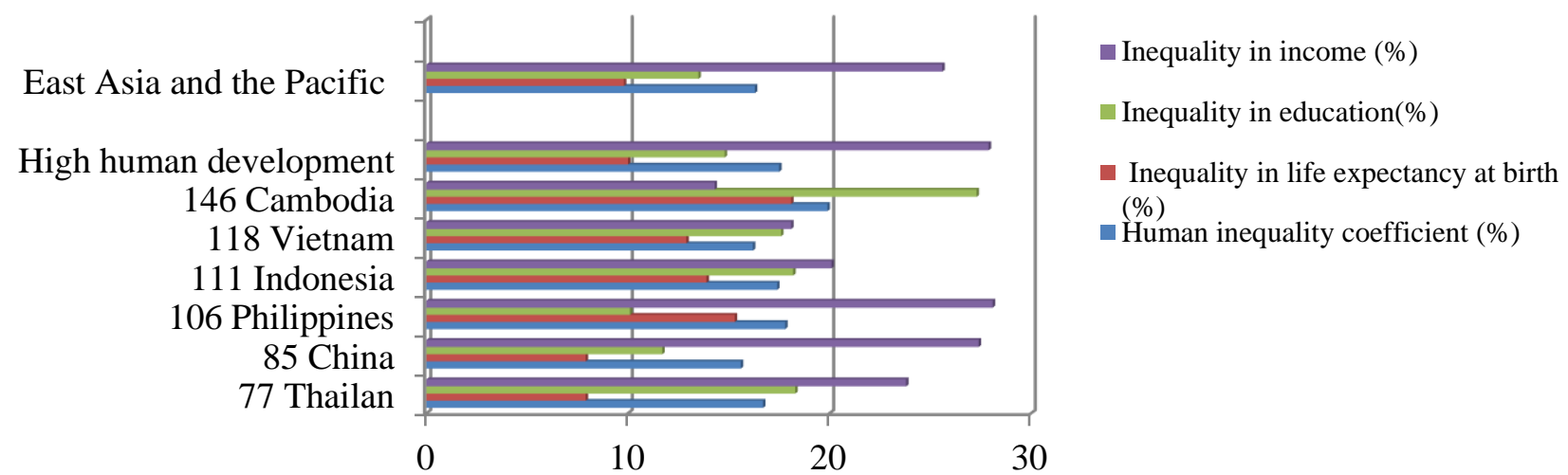

Fig 1. Comparing Vietnam's human inequality coefficient and component indicators

Compared to China, Vietnam has a higher human inequality coefficient. In terms of component indicators, the inequality in income is less, while the inequality in education and health care is greater than in China. Therefore, to improve the human equality even more, Vietnam needs to focus on improving the equality in education and health care.

Challenges in Vietnam's Human Development Process

Although Vietnam has achieved many remarkable achievements in human development, there are still many challenges and difficulties ahead that need to be overcome to continue human development, to enter a high human development group, even very high HDI group in the future. One of the main reasons for the slowdown in Vietnam's human development growth rate in recent years and worse than some other countries is gender inequality and disparities among regions and people groups.

\section{Gender gap}

The value of Vietnam's gender inequality index (GII) was 0.314 , standing 68th out of 162 countries in 2018. According to the GII ranking, Vietnam is more gender equality than Thailand, Philippines, Indonesia, India, Laos, Myanmar and Cambodia but more gender inequality than Korea, Malaysia and China. Vietnam has a lower GII value of the Medium Human Development group and the High Human Development group, higher than the GII of East Asia and Pacific group 0.004 points. Viet Nam's gender inequality has generally improved quite well, but some aspects of gender gap still need to be improved much more, as shown in table 4.

Table 4: Vietnam's GII in 2018 compared to selected countries and groups

\begin{tabular}{|c|c|c|c|c|c|c|c|c|}
\hline \multirow{3}{*}{$\begin{array}{l}\text { HDI ranking, } \\
\text { Country/Region }\end{array}$} & \multicolumn{2}{|c|}{ GII } & \multirow{2}{*}{$\begin{array}{c}\begin{array}{c}\text { Maternal } \\
\text { mortality } \\
\text { ratio }\end{array} \\
\text { Per } \\
\text { 100,000 } \\
\text { live births }\end{array}$} & \multirow{2}{*}{$\begin{array}{c}\text { Adolescent } \\
\text { birth rate }\end{array}$} & \multicolumn{2}{|c|}{$\begin{array}{c}\text { Population with at } \\
\text { least some secondary } \\
\text { education }\end{array}$} & \multicolumn{2}{|c|}{$\begin{array}{c}\text { Labor force } \\
\text { participation } \\
\text { rate }\end{array}$} \\
\hline & Value & Ranking & & & Female & Male & Female & Male \\
\hline & 2018 & 018 & 2015 & $\begin{array}{l}\text { Average of } \\
2015-2020\end{array}$ & 2018 & 2018 & 2018 & 2018 \\
\hline $\begin{array}{r}22 \text { Korea } \\
\text { (Republic of) }\end{array}$ & 0.058 & 10 & 11 & 1.4 & 89.8 & 95.6 & 52.8 & 73.3 \\
\hline 61 Malaysia & 0.274 & 58 & 4 & 13.4 & 79.8 & 81.8 & 50.9 & 77.4 \\
\hline 77 Thailand & 0.377 & 84 & 20 & 44.9 & 43.1 & 48.2 & 59.5 & 76.2 \\
\hline 85 China & 0.163 & 39 & 27 & 7.6 & 75.4 & 83 & 61.3 & 75.9 \\
\hline 106 Philippines & 0.425 & 98 & 114 & 54.2 & 75.6 & 72.4 & 45.7 & 74.1 \\
\hline 111 Indonesia & 0.451 & 103 & 126 & 47.4 & 44.5 & 53.2 & 52.2 & 82 \\
\hline 118 Vietnam & 0.314 & 68 & 54 & 30.9 & 66.2 & 77.7 & 72.7 & 82.5 \\
\hline 129 India & 0.501 & 122 & 17 & 13.2 & 39 & 63.5 & 23.6 & 78.6 \\
\hline $140 \mathrm{Laos}$ & 0.463 & 110 & 197 & 65.4 & 35 & 46 & 76.8 & 79.7 \\
\hline 145 Myanmar & 0.458 & 106 & 178 & 28.5 & 28.7 & 22.3 & 47.7 & 77.3 \\
\hline 146 Cambodia & 0.474 & 114 & 161 & 50.2 & 15.1 & 28.1 & 75.2 & 87.6 \\
\hline
\end{tabular}




\begin{tabular}{|c|c|c|c|c|c|c|c|c|}
\hline $\begin{array}{l}\text { High Human } \\
\text { Development }\end{array}$ & 0.331 & - & 56 & 33.6 & 68.9 & 74.5 & 53.9 & 75.6 \\
\hline Medium Human & & & & & & & & \\
\hline Development & 0.501 & - & 198 & 34.3 & 39.5 & 58.7 & 32.3 & 78.9 \\
\hline East Asia and the & & & & & & & & \\
\hline Pacific & 0.31 & - & 62 & 22 & 68.8 & 76.2 & 59.7 & 77 \\
\hline
\end{tabular}

On indicators of population with at least secondary education level, 66.2 percent of women in Vietnam are at least secondary education level, 11.5 percentage points less than the $77.7 \%$ in men. Participation rates in the labor market for women is $72.7 \%$ Vietnam, less 9.8 percentage points compared with $82.5 \%$ for men. In Vietnam, for every 100,000 safe births, 54 women die due to causes relating pregnancy, higher than many countries in Asia such as (Korea, Malaysia, Thailand and China), showing that Vietnam still needs to improve on this issue. In 2018, the adolescent birth rate of Vietnam was 30.9, higher than that of Malaysia, China, India and Myanmar and the average rate of East Asia and the Pacific. As such, Viet Nam needs to make more efforts to reduce gender inequality in maternal mortality, adolescent birth rates, simultaneously, to reduce the difference between men and women in educational attainment and labor market participation. Minimizing these inequalities will narrow the gender gap, minimize inequality, minimize the loss in HDI, and contribute to the improvement of Vietnam's human development.

Disparities among regions and population groups

Global multidimensional poverty statistics in 2018 show Vietnam's remarkable progress in the national average multidimensional poverty rate. In 2018, Vietnam's multidimensional poverty index was 0.0197. Vietnam's multidimensional poverty rate is $4.9 \%$, lower than the multidimensional poverty rates of some countries such as Indonesia (7\%), Philippines (5.8\%) and the average rate of East Asia and the Pacific (42.3\%), but higher than China (3.9\%), Thailand (0.8\%). 5.6 percent of Vietnam's population (5,369 thousand people) is classified as Population vulnerable to multidimensional poverty, the lowest among compared countries and the East Asia and Pacific region, as shown in table 5.

Table 5: Vietnam's MPI in 2018 compared with selected countries and groups

\begin{tabular}{lccc}
\hline Country/Region & MPI & $\begin{array}{c}\text { Population lives in } \\
\text { multidimensional poverty }\end{array}$ & $\begin{array}{c}\text { Population vulnerable to } \\
\text { multidimensional poverty }\end{array}$ \\
\cline { 3 - 4 } & value & $(\boldsymbol{\%})$ & $\mathbf{( \% )}$ \\
\hline Cambodia & 0.17 & 32.2 & 21.1 \\
China & 0.016 & 3.9 & 17.1 \\
India & 0.123 & 27.9 & 19.3 \\
Indonesia & 0.028 & 7 & 9.1 \\
Laos & 0.108 & 23.1 & 21.2 \\
Myanmar & 0.176 & 38.3 & 7.3 \\
Philippines & 0.024 & 5.8 & 7.2 \\
Thailand & 0.003 & 0.8 & 5.6 \\
Vietnam & 0.019 & 4.9 & 14.9 \\
East Asia and the Pacific & 0.024 & 42.3 & \\
\hline
\end{tabular}

The poverty data show significant disparities at the local level and across population groups. The rate of multidimensional poor households is $1.5 \%$ in urban areas while it is $9.6 \%$ in rural areas. The highest rate of multidimensional poverty is found in the Northern Midlands and Mountains (18.4\%), followed by the Central Highlands (13.9\%) and the North and South-Central Coast (8.7\%). Meanwhile, the lowest rate of multidimensional poor households is in the Southeast region $(0.6 \%)$. The difference in rates of multidimensional poverty by region shows that the cause of the lack of income, education, health insurance, housing, sanitation, and resources may be due to limitations in supply and access to social services, as shown in figure 2. 


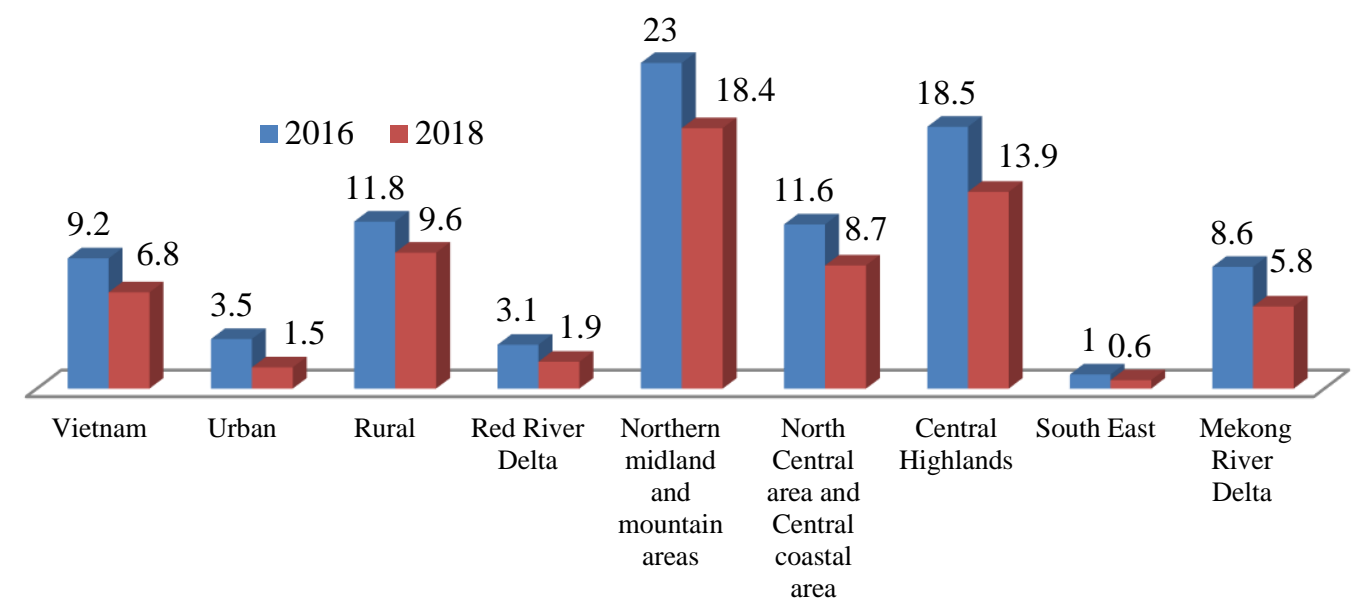

Fig 2. Proportion of multidimensionality poor households by urban, rural and by region in Vietnam in 2016 and 2018 (\%) (Source: Vietnam's General Statistics Office, 2020)

In addition to regional differences, multidimensional poverty rate among population groups also has huge disparities. While the multidimensional poverty rate among Kinh people was only $3.7 \%$ in 2018 , this rate is very high in some ethnic groups such as: 61.0\% among H'Mong, 29.1\% among Dzao, $17.1 \%$ among Khmer, 9.8\% among Thai and 30.7\% among other ethnic groups, as shown in figure 3.

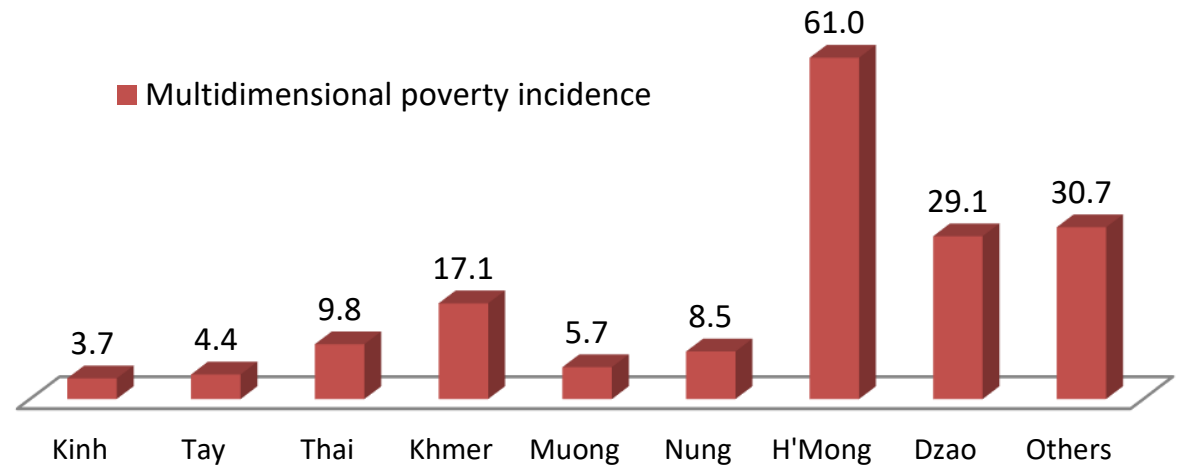

Fig 3. Multidimensional poverty rates in Vietnam

Disparities among groups of people will hinder human equality and human development of each nation. In order to improve the disparities among population groups, Vietnam needs to attach importance to cultural and traditional issues, to improve the socio-economic life of the ethnic minorities groups, in order to solve their geographical, economic, cultural and linguistic barriers.

\section{CONCLUSIONS}

Vietnam has consistently chosen the direction of human development and ensures equality in the country's socioeconomic development strategies and has achieved significant growth in human development with the average growth rate of HDI at $1.36 \%$ during $1990-2018$, along with a slow increase in inequality. This makes Vietnam one of the countries with the highest HDI growth rate in the world. Although Vietnam's HDI ranking in 2018 is 118 out of 189 countries, the rate of loss in human development due to inequality is lower than many countries with higher HDI, and lower than the average rate of medium human development group and East Asia and Pacific region. Despite great progress on gender equality, Vietnam needs to narrow the gender gap in education, in the participation in the labor market, and reduce the number of women who die due to causes relating to pregnancy and the adolescent birth rate. In addition, to reduce inequality, it is necessary to reduce disparities among regions and between groups of people. Despite great progress in multidimensional poverty reduction at the national level, Vietnam still has large disparities among regions and population groups. The multidimensional poverty rate is $1.5 \%$ in urban areas while the rate in rural areas is $9.6 \%$. The highest rate of multi-dimensionally poor household is in the Northern Midlands and Mountains (18.4\%), and the lowest is in the Southeast $(0.6 \%)$. The multidimensional poverty data of Vietnam also show significant differences between population groups. The multidimensional poverty rate of the Kinh is $3.7 \%$ while this rate is $61.0 \%$ 
for the H'Mong, 29.1\% for the Dao and $17.1 \%$ for the Khmer. In addition to the two major challenges in gender gaps and disparities among regions and groups of people, the study also pointed out the problems that Vietnam needs to overcome to improve HDI, which is the need to raise per capita income, improve education indicators, and improve the equity in education and health care.

\section{References}

[1]. Ann Vo. Vietnam - Human Capital as a Key Driver for Economic Growth - An Investigation of Vietnam's Economy and Binding Constraints. Final Country Report. Graduate School of 2. Public and International Affairs, 2016.

[2]. E. Vinot and R. Trigui, "Optimal energy management of HEVs with hybrid storage system," Energy Conversion and Management, vol. 76, pp. 437-452, Dec. 2013.

[3]. D. C. Thomas, "Cross-Cultural Management," Management, Sep. 2014.

[4]. Farhad Noorbakhsh. Human Development and Regional Disparities in India. Development Economics Research Conference on Inequality, Poverty and Human Well-being, Helsinki. Finland 30-31 May 2003.

[5]. UNDP. Vietnam's Human Development Report, 2009.

[6]. http://hdr.undp.org/en/countries/profiles/VNM. Accessed on 23.3.2020.

[7]. UNDP. Human Development Reports 1990-2019. http://hdr.undp.org/en/global-reports. Accessed on 20.3.2020.

[8]. Vietnam's General Statistics Office. https://www.gso.gov.vn/Default.aspx?tabid=217. Accessed on 28.3.2020.

[9]. D. Karamanis, "Management of moderate wind energy coastal resources," Energy Conversion and Management, vol. 52, no. 7, pp. 26232628, Jul. 2011.

[10]. A. P. Roskilly and M. Ahmad Al-Nimr, "Sustainable Thermal Energy Management," Energy Conversion and Management, vol. 159, pp. 396-397, Mar. 2018. 